Clark, H. H., \& Chase, W. G. On the process of comparing sentences against pictures. Cognitive Psychology, 1972, 3 , 472-517.

Paivio, A. Imagery and verbal processes. New York: Holt, $R$ inehart, \& Winston, Inc., 1971.

Posner, M. I. Abstraction and the process of recogniton. In G. Bower and J. T. Spence (Eds.), Psychology of learning and motivation, Vol. 3. New York: Academic Press, 1969.
Shepard, R N \& Chipman, S, Second-order isomorphism of internal representations: Shapes of states. Cognitive Psychology, 1970, 1, 1-17.

Tversky, B Pictorial and verbal encoding in a short-term memory task. Perception \& Psychophysics, 1969, 6, 225-233.

(Received for publication August 5, 1974.)

\title{
Reinforcement probability and concurrent operants
}

\author{
JORDAN ROS ENBE RG * \\ California State University, Hayward, California 94542
}

\begin{abstract}
When reinforcements for concurrent oyerants are programmed by independent variable-interval schedules of reinforcement, the relative response rate obtained for each operant is found to approximate the relative reinforcement rate for that operant. This relationship, called matching, is a necessary consequence of a maximizing principle which states that the operant emitted is the one having the momentarily greater reinforcement probability. Matching, however, can come about in other ways as well. To test the maximizing principle rats were trained to respond on either one of two levers. Whether a leverpress was reinforced was governed by a random process having a constant reinforcement probability which was not necessarily the same for the two levers. It was found that, after a few sessions' exposure, responding occurred nearly exclusively to the lever having the greater reinforcement probability as predicted by the maximizing principle.
\end{abstract}

Switching between concurrent operants is sometimes attributed to local changes in reinforcement probability (Catania, 1966; Shimp, 1966, 1969). It is held that the operant having the momentarily greater reinforcement probability will be emitted. This "momentary maximizing" principle (Shimp, 1966) is offered to account for various properties of the response distributions, such as relative response rate and changeover rate, obtained under concurrent schedules of reinforcement.

The relevance of the momentary maximizing principle to free operant behavior is supported by an examination of concurrent variable interval-variable interval schedules. These schedules arrange average reinforcement rates for the concurrent operants. The probability of a response being reinforced is not explicitly programmed. Instead, reinforcement probability is determined by the programmed rate and distribution of reinforcements interacting with the obtained rate and distribution of responses. This dependence of reinforcement probability on properties of responding makes the momentary reinforcement probabilities unpredictable and poses an obstacle to empirical validation of the momentary maximizing

*This paper is sponsored by Stephen Winokur, who takes full editorial responsibility. Reprints may be obtained from Jordan Rosenberg, Department of Psychology, California State University, Hayward, California 94542. principle. Instead, the principle has become an assumption which has been combined in formal analysis with characteristics of the reinforcement scheduling procedures. The most important consequence of such an analysis is the prediction of the matching law (Shimp, 1969) which states that the relative rate of responding and the relative rate of reinforcement are approximately equal in each component of a concurrent schedule of reinforcement. Since this matching law is already well established for concurrent variable interval-variable interval schedules (Herrnstein, 1961, 1970) the momentary maximizing principle is supported.

The experiment reported here sought to test the momentary maximizing principle directly by explicitly arranging reinforcement probabilities for two concurrent operants. The reinforcement probability associated with each operant did not change during an experimental session. Hence, when the two probabilities were unequal the momentary maximizing principle predicted exclusive emission of the operant having the greater reinforcement probability. In the terminology of Schoenfeld and Cole (1972) the procedure used was a concurrent random ratio-random ratio schedule of reinforcement.

\section{METHOD}

Subjects

The Ss were four experimentally naive male Albino rats 120 
days old at the start of the experiment and maintained at $80 \%$ of their free-feeding weight.

\section{Apparatus}

The apparatus consisted of a conventional two-lever operant conditioning chamber, commercially obtained, with a feeder supplying 45-mg Noyes pellets. Experimental events were programmed by means of solid state logic modules. Data were recorded on electro-mechanical impulse counters.

\section{Procedure}

A reinforcement probability, the independent variable, was assigned to each lever and remained in effect for several sessions. Whether a particular response was reinforced was determined by a random process that was independent of all prior responses and reinforcements. The reinforcement probabilities employed were selected from the set $(0.200,0.040,0.008)$.

The method for programming reinforcement probability has been described by Brandauer (1958) and by Schoenfeld and Cole (1972). A response was reinforced if, and only if, it coincided with the on period of an on-off cycle whose total duration was set smaller than the smallest anticipated interresponse time. In the present experiment cycle duration was $62.5 \mathrm{msec}$ or less. The reinforcement probability was the fraction that the on portion represented of the cycle duration.

Relative response rate and changeover rate, the dependent variables, were calculated from the recorded data: the number of responses to each lever, the number of changeovers to each lever. Relative response rate is the ratio of the number of responses to one lever to the total number of responses. Changeover rate is the ratio of the number of changeover responses to the total number of responses

A pair of reinforcement probabilities remained in effect for 12 sessions (S 511) or for 6 sessions (Ss 510, 501, and 502). For S 511 and 510, when an unequal pair of reinforcement probabilities was introduced, the greater was always assigned to the lever having the smaller relative response rate. For Ss 501 and 502, this was sometimes the case and sometimes not. Different Ss received different pairs of values of the independent variable as indicated below.

Experimental sessions were run 6 days per week and each lasted for approximately $75 \mathrm{~min}$. Initially, Ss were trained to respond to both levers. Over a period of 6-8 days, the reinforcement probabilities were gradually reduced from 1.00 to the values that would be used during the experiment proper.

\section{RESULTS}

Relative response rate, changeover rate, and total responses are presented in Table 1 for all experimental sessions of S 511. Four pairs of reinforcement probabilities were employed in the order presented in Table 1. Each pair was in effect for 12 consecutive sessions.

The relative response rates of S 511 tended to be near the extreme values of 0 and 1 . Changeovers tended to be infrequent in all sessions. Extreme relative respone rates were found both when the two reinforcement probabilities were equal and when they were unequal. When the unequal pairs of reinforcement probabilities were employed, the lever having the greater reinforcement probability became, after a few sessions' exposure, the one receiving essentially all the responses. By introducing a new pair of reinforcement probabilities and assigning the lesser of the two probabilities to the lever whose relative response rate was 1.0 , that relative response rate could be reversed from 1.0 to 0.0 . This reversal required only a few sessions' exposure and could be largely accomplished in the first session. It may be noted that when the reinforcement probabilities were changed from $(0.040,0.040$ to $0.040,0.200)$, a new reinforcement probability was assigned only to the lever receiving essentially none of the responses. Nevertheless, within three sessions relative response rate was affected.

Relative response rate, changeover rate and total responses are presented in Table 2 for Ss 510,501 , and 502 . Each set of values presented was obtained in the last of six sessions employing the reinforcement probability pairs indicated. For these data, too, relative response rate tended to be extreme. Responding occurred predominantly to the lever having the greater

Table 1

The Relative Rate of Responding and the Changeover Rate for Each Experimental Session as a Function of the Pair of Reinforcement Probabilities Programmed for the Two Levers*

\begin{tabular}{|c|c|c|c|c|c|c|c|c|c|c|c|}
\hline \multicolumn{3}{|c|}{$(0.040,0.040)$} & \multicolumn{3}{|c|}{$\begin{array}{l}\text { Reinforcement } \\
(0.040,0.200)\end{array}$} & \multicolumn{3}{|c|}{$\begin{aligned} \text { Probabilities } & (\mathrm{Pl}, \mathrm{Pr}) \\
& (0.040,0.040)\end{aligned}$} & \multicolumn{3}{|c|}{$(0.008,0.040)$} \\
\hline Rl & $\mathrm{Co}$ & $\mathrm{N}$ & Rl & $\mathrm{Co}$ & $\mathbf{N}$ & Rl & $\mathrm{Co}$ & $\mathbf{N}$ & Rl & $\mathrm{Co}$ & $\mathrm{N}$ \\
\hline 0.84 & & 2045 & 1.00 & 0.004 & 8560 & 0.79 & 0.005 & 6823 & 0.24 & 0.005 & 12009 \\
\hline 0.99 & 0.008 & 3744 & 1.00 & 0.002 & 6916 & 0.95 & 0.004 & 8000 & 0.01 & 0.001 & 8949 \\
\hline 0.99 & 0.005 & 3730 & 0.37 & 0.011 & 2070 & 0.99 & 0.004 & 7821 & 0.01 & 0.001 & 10145 \\
\hline 1.00 & 0.003 & 3856 & 0.03 & 0.003 & 1781 & 1.00 & 0.003 & 8855 & 0.01 & 0.001 & 6786 \\
\hline 1.00 & 0.001 & 5278 & 0.00 & 0.000 & 1398 & 1.00 & 0.003 & 7406 & 0.00 & 0.000 & 8773 \\
\hline 1.00 & 0.000 & 6138 & 0.00 & 0.001 & 1662 & 0.99 & 0.002 & 7348 & 0.01 & 0.002 & 9021 \\
\hline 1.00 & 0.001 & 4795 & 0.02 & 0.002 & 1810 & 1.00 & 0.003 & 8332 & 0.00 & 0.001 & 9392 \\
\hline 1.00 & 0.001 & 8372 & 0.00 & 0.003 & 1963 & 1.00 & 0.003 & 6583 & 0.00 & 0.001 & 10246 \\
\hline 1.00 & 0.001 & 7530 & 0.00 & 0.001 & 1739 & 1.00 & 0.003 & 8238 & 0.00 & 0.001 & 7942 \\
\hline 1.00 & 0.001 & 7540 & 0.00 & 0.001 & 2040 & 1.00 & 0.001 & 8707 & 0.01 & 0.002 & 10017 \\
\hline 1.00 & 0.002 & 8606 & 0.00 & 0.001 & 1607 & 1.00 & 0.001 & 8457 & 0.00 & 0.001 & 9101 \\
\hline 1.00 & 0.000 & 8486 & 0.00 & 0.001 & 2143 & 1.00 & 0.001 & 11011 & 0.00 & 0.000 & 9692 \\
\hline
\end{tabular}

Note-Pl = reinforcement probability, left lever; $\operatorname{Pr}=$ reinforcement probability, right lever; $N=$ total responses, both levers; $R l=$ relative rate of responding, left lever; and $C o=$ changeovers as a proportion of total responses.

${ }^{*}$ Data are from $S 511$. 
Table 2

The Relative Rate of Responding and the Changeover Rate Obtained During the Last Session of a Six-Session Series as a Function of the Pair of Reinforcement Probabilities Programmed for the Two Levers

\begin{tabular}{clccc}
\hline & $(\mathrm{P} 1, \mathrm{Pr})$ & $\mathrm{R} 1$ & $\mathrm{Co}$ & $\mathrm{N}$ \\
\hline & $(0.040,0.040)$ & 0.81 & 0.002 & 5689 \\
& $(0.040,0.200)$ & 0.20 & 0.005 & 1654 \\
S 510 & $(0.040,0.040)$ & 0.94 & 0.001 & 6484 \\
& $(0.008,0.200)$ & 0.00 & 0.002 & 1197 \\
& $(0.040,0.040)$ & 0.00 & 0.001 & 8252 \\
& $(0.040,0.008)$ & 1.00 & 0.003 & 9526 \\
S 501 & $(0.040,0.008)$ & 0.99 & 0.008 & 3248 \\
& $(0.040,0.200)$ & 0.01 & 0.006 & 1073 \\
& $(0.040,0.008)$ & 0.99 & & 4473 \\
S 502 & $(0.200,0.040)$ & 0.98 & 0.032 & 969 \\
& $(0.008,0.040)$ & 0.48 & 0.415 & 578 \\
& $(0.008,0.040)^{*}$ & 0.00 & 0.006 & 5666 \\
& $(0.200,0.040)$ & 0.82 & 0.022 & 1337 \\
\hline
\end{tabular}

Note $-\mathrm{Pl}=$ reinforcement probability, left lever $; \mathrm{Pr}=$ reinforcement probability, right lever; $N=$ total responses, both levers; $R l=$ relative rate of responding, left lever; $C o=$ changeovers as a proportion of total responses.

${ }^{*}$ Redetermined following intervening sessions.

reinforcement probability when the two probabilities were unequal. Changing the reinforcement probabilities could change relative response rate from one extreme to the other within only a few sessions. Changeovers tended to be infrequent.

For all of the experimental sessions considered so far, when unequal reinforcement probabilities were introduced, the greater was assigned to the lever which, in the immediately preceding sessions, received the lesser number of responses. The effect of this change in reinforcement probabilities was to reverse exclusive responding from one lever to the other. It is possible, however, that any change in the reinforcement probabilities might have produced the same result. In order to test this possibility, Ss 501 and 502 were exposed to additional sessions in which reinforcement probabilities changed subject to the restriction that the lever which had the greater reinforcement probability after the change was the same lever that had had the gerater reinforcement probability before the change.

Sometimes the greater reinforcement probability was changed while other times it was the lesser that changed. Sometimes the disparity between the two reinforcement probabilities increased while other times the disparity decreased. None of these changes produced a discernible effect on relative response rate or changeover rate.

\section{DISCUSSION}

The results of the present experiment may be summarized as follows: the operant emitted was the operant having the greater reinforcement probability. This restates the momentary maximizing principle as it applied to the present experimental procedures. Support for the momentary maximizing principle must be qualified, however, in the following ways.

In the present experiment there were no within-session changes in reinforcement probability. Emission of the operant having the greater reinforcement probability did not require any changeovers. Whether the momentary maximizing principle applies to the more general situation where the reinforcement probabilities change from moment to moment and where changeovers are required is not shown by the present data. Extension of the momentary maximizing principle to the more general situation must be demonstrated before the momentary maximizing principle can be accepted as providing a satisfactory account of behavior under such schedules of reinforcement as concurrent VI-VI.

If, at the beginning of an experimental session, both operants are emitted about equally often, then the operant having the greater reinforcement probability is also the operant more likely to be first reinforced in that session. Even when the operants are not emitted equally often, the operant more likely to be first reinforced is, in most cases, the operant having the greater reinforcement probability. It is not clear which variable, greater reinforcement probability or the first reinforcement, determines relative response rate since, in the present experiments as in many experiments on concurrent operants, the two variables are confounded. That the first reinforcement may be important in determining relative response rate has been shown by McDiarmid and Rilling (1965) for concurrent interval schedules of reinforcement.

The present data are pertinent to considerations of the matching law in its general form (Herrnstein, 1970). The matching law records the equality observed between relative response rate and the relative value of the independent variable when the independent variable is reinforcement rate (Herrnstein, 1961), reinforcement amount (Catania, 1963), or reinforcement immediacy (Chung and Herrnstein, 1967). One finding of the present study is that this equality does not extend to situations in which the independent variable is reinforcement probability. Relative response rate does not equal relative reinforcement probability.

In its earlier form, the independent variable of the matching law was restricted to reinforcement rate (Herrnstein, 1961). In that form, the matching law describes the present data. Whenever one operant occurs exclusively, its relative response rate and its relative reinforcement rate are both necessarily equal to 1.0. However, this restricted form of the matching law does not hold for situations in which reinforcement amount or reinforcement immediacy are varied.

\section{REFERENCES}

Brandauer, C. M. The effect of uniform probabilities of reinforcement upon the response rate of the pigeon. Unpublished doctoral thesis, Columbia University, 1958.

Catania, A. C. Concurrent performances: a baseline for the study of reinforcement magnitude. Journal of the Experimental Analysis of Behavior, 1963, 6, 299-300.

Catania, A. C. Concurrent operants. In W. K. Honig (Ed.) Operant behavior. New York City: Appleton-Century-Crofts, 1966.

Chung, S. H., \& Herrnstein, R. J. Choice and delay of reinforcement. Journal of the Experimental Analysis of Behavior, 1967, 10, 67-74.

Herrnstein, R. J. Relative and absolute strength of response as a function of frequency of reinforcement. Journal of the Experimental Analysis of Behavior, 1961, 4, 267-272.

Herrnstein, R. J. On the law of effect. Journal of the Experimental Analysis of Behavior, 1970, 13, 243-266.

McDiarmid, C. G., \& Rilling, M. E. Reinforcement delay and reinforcement rate as determinants of schedule preference. Psychonomic Science, 1965, 2, 195-196.

Schoenfeld, W. N., \& Cole, B. K. Stimulus Schedules: The t- $\tau$ systems. New York City: Harper and Row, 1972.

Shimp, C. P. Probabilistically reinforced choice behavior in pigeons. Journal of the Experimental Analysis of Behavior, $1966,9,443-455$.

Shimp, C. P. Optimal behavior in free-operant experiments. Psychological R eview, 1969, 76, 97-112.

(R eceived for pbulication A ugust 29, 1974.) 